\title{
Toyin Falola and Akintunde Akinyemi (Eds). Encyclopedia of the Yoruba. Bloomington and Indianapolis: Indiana University Press, 2016. 371pp.
}

\author{
Ibrahim A. Odugbemi \\ University of Ibadan, Nigeria
}

Encyclopedia of the Yoruba is a single-volume encyclopedia that is comprised of 285 entries of short essays written by 188 authors who are predominantly scholars and academic researchers from Africa, Europe and North America. The different word-ranges of the essays vary from 1000 words (for 78 entries) to 750 words (for 88 entries) and 500 words (for 119 entries). Across these entries, the encyclopedia gives a complex, yet detailed, presentation of the Yorùbá, a dominant ethnic group in West Africa and the most prominent African cultural population, identity and presence in the African diaspora including North America, the Caribbean and South America. It presents the Yorùbá with respect to their involvements in, and interactions with, different sociocultural experiences, practices and expressions by "emphasizing the peculiarities, features, and commonalities of the people" (xi).

Following an alphabetical ordering, each entry in the encyclopedia is complete on its own as it examines and discusses a subject, subject matter, concept or topic that shares an affiliation with the Yorùbá world in time (the traditional past in all its distant and intricate temporal dimensions and the modern present in all its complex interrelations) and/or space (Yoruba homes across West Africa and the African diaspora. Such concentrations of the entry include persons/personalities, demographics, worldviews and cosmological values and elements, and several material and non-material aspects of the Yorùbá culture and folklore, and their corresponding affiliates.

It is important to add that the completeness of the entries is considerably informed by the suitability of the word-ranges used. It is commendable that 
the editors are able to determine the word-range that fits the discourse of every entry and the authors are also able to conform. By writing across the various word-limits, the authors have been able to give adequate information about their subjects of discussion. Each word-limit is moderate enough to convey the basic information on the subject or topic of every entry.

While the alphabetical arrangement of the entries seems to make them inorganic, there is an adequate use of cross-references at the end of almost each entry. This caters for interconnections and complementary links between two or more entries, and thus gives the encyclopedia some measure of organic structure. A reader that seeks to know about a subject in the volume is therefore bound to gather as much extensive information as possible by consulting related entries apart from the main entry on the subject. In addition, the entries all have bibliographical references which users of the encyclopedia will find useful for further reading.

Unarguably, this volume appropriately qualifies as an encyclopedia. It is an invaluable resource that presents ample and invaluable information about the Yorùbá. Nevertheless, an addition of some more entries may be expedient in making the subsequent edition of the encyclopedia serves its readers better. For instance, entries on some persons will be found worthwhile: Herbert Macaulay, who is considered to be the founder of Nigerian nationalism; Candido Da Rocha, Lagos first millionaire and native of Ilesha who was born of a returnee slave; Funmilayo Ransome Kuti, a political campaigner and foremost women's rights activist; Wande Abimbola, a professor of Yorùbá language and literature and prominent Ifá scholar and practitioner; and Taiwo Akinkunmi, who designed the flag of Nigeria. In addition, there is need for an entry on twins (ibeji) considering the fact that they are phenomenal and revered personalities as evident in Yorùbá belief system and orality. The entries related to Islam may also be supported with an entry on "Ààre Musulumi" (president of the Muslims). This is an Islamic chieftaincy title among Yorùbá Muslims given to honor a person as the number one Muslim in Southwest Nigeria.

Similarly, entries on places like Abeokuta, Lagos and Badagry will also be good additions to the Encyclopedia. Like Ife and Ibadan which already have entries in the Encyclopedia, these other places also have socio-historical narratives that are crucial to understanding the development of the Yorùbá nation, identity and presence across times, the traditional past and the modern present alike. It will also be a good idea to have an entry on the physical and natural components of the Yorùbá world such as water bodies, hills and rocks. This is because some of them serve religious, social and economic purposes in addition to having mythical and oral historical narratives. In this respect, the editors could consider inviting entries on the River Oya (Niger), River Yewa, 
River Ogun, River Osun, Ikogosi Warm Spring, Olumirin Waterfall, Olumo Rock and Idanre Hill.

It would also be a good idea if some authors could incorporate more ideas and information into their essays. For instance, the first essay in the Encyclopedia on "Abiola, Moshood Kasimawo Olawale" needs to have a clear reference to Chief Ernest Shonekan. This is because among other issues surrounding his emergence as head of the interim government on August 26, 1993, Chief MKO Abiola was appointed as the vice president. Therefore, it may be necessary that the author of this essay expatiate on his idea of "quick succession of administration" (20) by giving the example of the emergence and fall of the interim government. The essay on "Comic Arts" could be enlarged to include contemporary practices especially as informed by the digital media and cinematic performances. The examples of Moses Olaiya with his Awada and Gbenga Adeboye, whose comic performances considerably qualify him as a major pioneer of the Nigerian Standup Comedy and whose varieties of media and cultural productions are distinctive in the Nigerian mainstream culture, would be much relevant in this respect. In a similar vein, the entry on "Media: Radio and Television" may have to recognize pioneering roles of Adebayo Faleti in the television industry and cinematic engagements. Also, the entry "Nollywood: Films and Cinema" could hint at the idea of the New Nollywood with respect to the pioneering and continually predominant efforts of Yorùbá filmmakers by also referring to Kunle Afolayan in addition to Tunde Kelani.

The Encyclopedia of the Yoruba is a huge and priceless contribution to studies in African and the black diaspora across different disciplines including literary and cultural studies, history, philosophy, religion, political science, sociology and psychology. The efforts of the authors and editors are sincerely commendable. The suggested recommendations should heighten the significance of the Encyclopedia in its next edition. 